PAEDIATRIC LUNG DISEASE

\title{
Open lung biopsy in neonatal and paediatric patients referred for extracorporeal membrane oxygenation (ECMO)
}

\author{
D Inwald, K Brown, F Gensini, M Malone, A Goldman
}

Thorax 2004;59:328-333. doi: 10.1136/thx.2003.010793

See end of article for authors' affiliations .....................

Correspondence to: Dr D Inwald, Portex Unit, Institute of Child Health, 30 Guilford Street, London WCIN IEH, UKK D.Inwald@ich.ucl.ac.uk

Received 28 May 2003 Accepted

9 December 2003

\begin{abstract}
Background: This study was undertaken to determine the usefulness, safety, and most appropriate timing of open lung biopsy in infants and children considered for and on extracorporeal membrane oxygenation (ECMO) for respiratory failure.

Methods: A retrospective review of children referred for consideration of and placed on ECMO in our institution in the period 1996-2002.

Results: 506 patients were referred, $15(3 \%)$ of whom underwent antemortem open lung biopsy (eight neonatal, four paediatric, and three cardiac patients). In the neonatal group open lung biopsy contributed to clinical decision making in all patients. Four neonates had a fatal lung dysplasia (three alveolar capillary dysplasia and one surfactant protein B deficiency) and treatment was withdrawn. Of the other four neonates, two had pulmonary hypoplasia, one had pulmonary lymphangiectasia, and one had meconium aspiration with mild barotrauma. Treatment was continued in these four patients and two survived. In the paediatric group the biopsies were of clinical relevance in two infants with pertussis who had lung infarction on biopsy in whom treatment was withdrawn. In the other two paediatric patients the biopsies were equivocal, treatment was continued, but both patients died. In the cardiac group, who presented perioperatively with pulmonary hypertension, the biopsies excluded a fatal lung dysplasia and severe pulmonary vascular disease but all three infants died. One patient had non-fatal bleeding complications. Conclusion: Open lung biopsy is clinically most useful when performed to diagnose fatal lung dysplasias in neonates and to confirm the presence of viable lung tissue in patients with acute lung injury due to pertussis infection.
\end{abstract}

$\mathrm{P}$ atients referred for extracorporeal membrane oxygenation (ECMO) with respiratory failure are almost always started on ECMO support without a histological diagnosis. There are two reasons for this approach. Firstly, particularly for neonates, the lung pathology is often known, reversible, and improves rapidly with a period of lung restfor example, meconium aspiration. Secondly, patients may be considered too sick for an open lung biopsy to be performed before ECMO, and ECMO can provide a way to support the patient without inducing ventilator associated lung injury while diagnosing and managing the underlying disease process. However, there are clear advantages in making a histological diagnosis in some infants and children referred for ECMO support. In neonatal respiratory failure, $6 \%$ of infants referred for ECMO have an underlying irreversible lung dysplasia which is incompatible with life. ${ }^{1}$ Older children may have irreversible pulmonary vascular or parenchymal disease. Open lung biopsy with histological diagnosis could provide a way to develop logical management pathways for patients with these conditions.

The aim of this study was to determine the usefulness, safety, and most appropriate timing of open lung biopsy in infants and children considered for and on ECMO for respiratory failure.

\section{METHODS}

A retrospective review was performed of the records of all children referred for and placed on ECMO who also underwent open lung biopsy in the period 1996-2002. Patients were excluded if their biopsy was taken after death or if it was an abnormal lobe or lung excised at surgery for therapeutic rather than diagnostic purposes. Information obtained included the age, gestation, admission diagnosis, length of stay, timing of the biopsy, diagnosis at discharge or death, and clinical usefulness of the biopsy. Biopsies were defined as being clinically useful if they yielded a histological diagnosis which aided clinical management.

\section{Indications for biopsy \\ Neonatal ECMO}

The indication for biopsy for neonates before or during their ECMO run was to confirm or exclude the presence of a fatal lung dysplasia (for example, a clear chest radiograph with severe hypoxia suggesting alveolar capillary dysplasia, a chest radiograph with extensive alveolar shadowing suggestive of surfactant protein B deficiency) or irreversible lung pathology (such as pulmonary hypoplasia or pulmonary lymphangiectasia). The aim of this strategy was to use the results to help to decide if ECMO should be offered or withdrawn. The purpose of the biopsies taken after decannulation was to determine if a further period of lung rest on ECMO should be offered or if treatment should be withdrawn.

\section{Paediatric ECMO}

The indication for biopsy for older children on ECMO commenced for acute hypoxaemic respiratory failure due to infection was to try to determine the severity of the acute lung injury and hence the potential for lung recovery. Biopsy specimens were taken from these children after 14-21 days of ECMO support when no lung recovery had occurred. 


\section{Cardiac ECMO}

The indication for biopsy in patients with cardiac disease was to determine the cause of unexplained hypoxaemia or pulmonary hypertension when surgically remediable residual lesions had been excluded by echocardiography or cardiac catheterisation.

\section{Surgical methodology}

Before and 48 hours after performing a lung biopsy our practice is to maintain a platelet count of $>150 \times 10^{9} / 1$, fibrinogen $>2 \mathrm{~g} / \mathrm{l}$, and activated clotting time 160-180 s. All procedures were performed in the intensive care unit or in the operating room under general anaesthesia. Depending on the macroscopic appearance of the lung tissue and ease of mobilisation, operators chose differing techniques to take the biopsy specimen and seal the lung. As diffuse disease was present in all cases, ease of surgical access was the prime consideration in determining the site of the biopsy. A single biopsy specimen was taken for histopathological examination in all cases. The suture line was tested for air leaks and careful haemostasis was performed. A chest drain was left in the pleural space and connected to an underwater seal drainage system.

\section{Histopathological methodology}

Biopsy specimens were fixed in $1 \%$ formaldehyde and embedded in wax. Sections $4 \mu \mathrm{m}$ thick were taken and stained with haemotoxylin and eosin and van Gieson's stain. Surfactant protein B staining was performed using previously described immunohistochemical techniques. ${ }^{2}$

\section{RESULTS}

\section{Demographic data}

During the review period (1996-2002) 310 patients were treated with ECMO, of whom 136 were neonatal, 66 were paediatric, and 106 were cardiac. Of these, $68 \%, 62 \%$, and $44 \%$ respectively survived to hospital discharge. 196 patients were also referred for consideration for ECMO support but did not receive it either because they improved with conventional management or because ECMO was contraindicated. Of the total of 506 patients, 15 (3\%) underwent antemortem open lung biopsy and fell within the entry criteria. We retrospectively reviewed the case notes and biopsy specimens of these patients. Of these 15 patients, eight were neonatal, four paediatric, and three cardiac. Three biopsies were performed before ECMO, nine during ECMO, and three after decannulation. Of the nine biopsies carried out while on ECMO, the median time from ECMO cannulation to biopsy was 7 days (range 1-28 days).

\section{Surgical considerations}

A limited anterolateral thoracotomy incision was the approach in 12 of the 15 cases. The side of the chest opened depended on factors such as the presence of pneumothorax/ effusions or chest drains. One of these 12 cases (case 8) was biopsied at the same time as surgical pleurodesis was performed for uncontrolled air leak following ECMO decannulation. Two biopsies were performed through a midline sternotomy as part of a primary open heart surgical procedure, when the possibility of additional lung pathology had been raised due to suprasystemic pulmonary artery pressures either preoperatively (case 15) or postoperatively (case 13). Video assisted thoracoscopy was used in one case (case 9) while on ECMO due to an organised haemothorax which was present before the biopsy. This procedure was used for diagnostic and therapeutic purposes. This patient had further haemorrhage following the biopsy and later died from failure of lung recovery and progressive right ventricular failure.
Clinical usefulness, safety, and timing of lung biopsies Neonatal ECMO

All three neonates who underwent open lung biopsy before ECMO for a suspicion of irreversible lung dysplasia had this confirmed. Two with persistent pulmonary hypertension of the newborn (PPHN), clear chest radiographs, and normally compliant lungs had alveolar capillary dysplasia (cases 2 and 3, fig 1). One with PPHN and bilateral alveolar shadowing on the chest radiograph had surfactant protein B deficiency (case 1, fig 2). None of these infants was offered ECMO support due to the irreversible nature of their lung pathology and all died.

Two neonates had an open lung biopsy while on ECMO support (at days 3 and 7 of their ECMO runs). The indication for the first of these (case 4) was bilateral chylous effusion and her biopsy confirmed the clinical suspicion of pulmonary lymphangiectasia. This infant later died despite aggressive conventional management after ECMO decannulation. The indication for the second biopsy was pulmonary hypoplasia on a background of intrauterine obstructive uropathy (case 5). This infant was biopsied after a week on ECMO as minimal lung recovery had occurred. The biopsy confirmed pulmonary hypoplasia, the infant was weaned from ECMO support and is a long term survivor.

Biopsy specimens were taken from three neonates following ECMO decannulation. The biopsy in the infant with meconium aspiration and uncontrolled air leak following ECMO decannulation (case 8) excluded a fatal lung dysplasia and the infant would have been offered ECMO again, had it been required. However, she was weaned from mechanical ventilation and is a long term survivor. Two neonates with PPHN were suspected of having a fatal lung dysplasia as they could not be weaned from mechanical ventilation after decannulation from ECMO. The first of these (case 7) had alveolar capillary dysplasia and the second (case 6, fig 3) had severe pulmonary hypoplasia. Treatment was withdrawn in both of these infants and both died. Thus, of the eight neonates from whom biopsy specimens were taken, six had a clinical suspicion of a fatal lung dysplasia confirmed and in all eight the biopsy result contributed to clinical decision making (table 1).

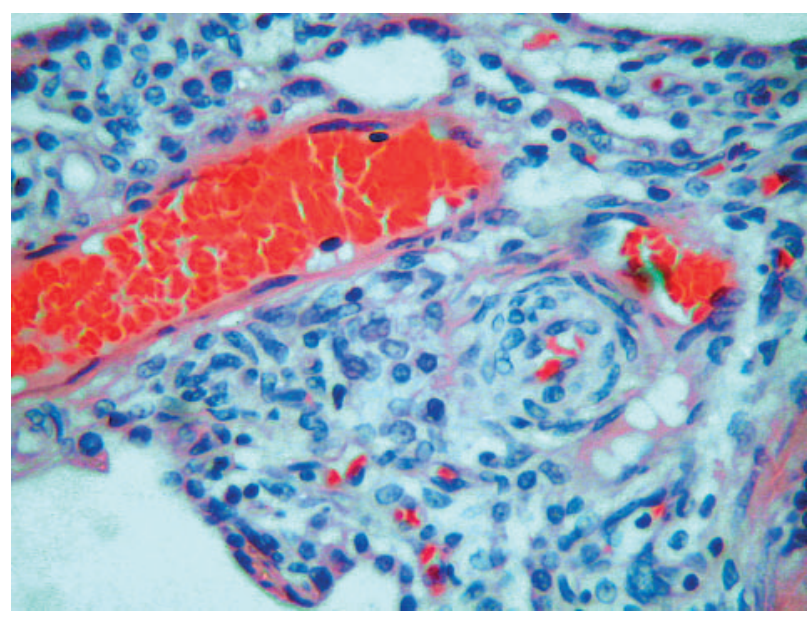

Figure 1 Alveolar capillary dysplasia. Elastic van Gieson stain showing widened alveolar walls with a marked deficiency of alveolar capillary vessels. Branches of pulmonary veins are side by side with and invested with the same adventitia as small pulmonary arteries, in contrast to their normal position in the interacinar septa. Branches of small interacinar arterioles show muscularisation of their walls. 


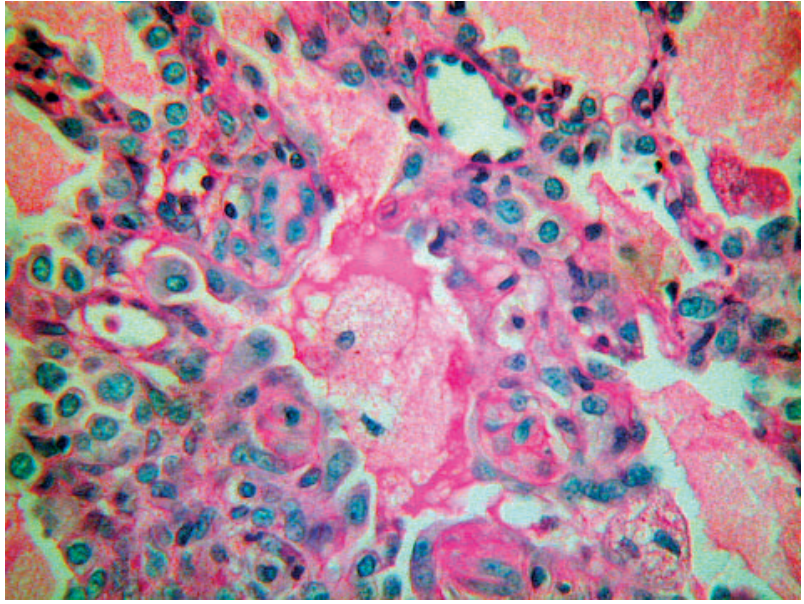

Figure 2 Surfactant protein B (SP-B) deficiency at low power showing alveolar proteinosis. Immunostaining (not shown) for surfactant B showed absent staining of type 2 pneumocytes. Studies carried out by $\mathrm{Dr}$ Nogee at Johns Hopkins University indicated that this patient was homozygous for a nonsense mutation in codon 9 of exon 1 in the SP-B gene.

\section{Paediatric ECMO}

Biopsy specimens were taken from all four paediatric patients while receiving ECMO support to determine the reversibility of the acute lung injury. Three had pertussis and biopsies were performed after 14,17 and 28 days of support following failure of lung recovery on ECMO (cases 10, 11 and 12, respectively). The biopsy specimen in case 11 showed interstitial fibrosis and alveolar wall thickening. On the basis of this result, the patient was continued on ECMO. He was later successfully decannulated from ECMO but died of progressive respiratory failure 7 days later. A post mortem examination revealed widespread lung infarction. The biopsy specimens of the other two infants with pertussis showed lung infarction (case 12, fig 4) and treatment was



Figure 3 Pulmonary hypoplasia. There is failure of development of the terminal bronchioles, some of which extend almost to the pleural surface. Alveolar spaces are sparse, poorly developed, and separated by connective tissue containing a scattering of chronic inflammatory cells.

withdrawn. The remaining child (case 9), who had adult respiratory distress syndrome (ARDS) secondary to pneumovirus infection, had a biopsy after 17 days of ECMO support which showed features of fibroproliferative ARDS. This patient had been started on steroid therapy for ARDS and would have been continued on ECMO had he not died of other causes (see above, table 2).

\section{Cardiac ECMO}

Biopsy specimens were taken from all three infants in this group to exclude an associated lung dysplasia or irreversible pulmonary vascular disease. Two infants with transposition of the great arteries (one with a ventricular septal defect, one with an intact ventricular septum) were placed on ECMO postoperatively after arterial switch procedures because of severe pulmonary hypertension. In one (case 13) the biopsy

Table 1 Neonatal ECMO cases

\begin{tabular}{|c|c|c|c|c|c|c|c|c|}
\hline $\begin{array}{l}\text { Case } \\
\text { no }\end{array}$ & $\begin{array}{l}\text { Admission } \\
\text { diagnosis }\end{array}$ & $\begin{array}{l}\text { Age at } \\
\text { referral } \\
\text { (days) }\end{array}$ & $\begin{array}{l}\text { Length of } \\
\text { ECMO run } \\
\text { (days) }\end{array}$ & $\begin{array}{l}\text { ECMO day } \\
\text { biopsy performed }\end{array}$ & Histological diagnosis & Management change & Outcome & Cause of death \\
\hline 1 & PPHN & 1 & - & Pre ECMO & $\begin{array}{l}\text { Surfactant protein B } \\
\text { deficiency }\end{array}$ & ECMO not offered & Died & $\begin{array}{l}\text { Respiratory } \\
\text { failure }\end{array}$ \\
\hline 2 & PPHN & 9 & - & Pre ECMO & $\begin{array}{l}\text { Alveolar capillary } \\
\text { dysplasia }\end{array}$ & ECMO not offered & Died & $\begin{array}{l}\text { Respiratory } \\
\text { failure }\end{array}$ \\
\hline 3 & PPHN & 18 & - & Pre ECMO & $\begin{array}{l}\text { Alveolar capillary } \\
\text { dysplasia }\end{array}$ & ECMO not offered & Died & $\begin{array}{l}\text { Respiratory } \\
\text { failure }\end{array}$ \\
\hline 4 & $\begin{array}{l}\text { Meconium } \\
\text { aspiration }\end{array}$ & 1 & 9 & 3 & $\begin{array}{l}\text { Pulmonary } \\
\text { lymphangiectasia }\end{array}$ & $\begin{array}{l}\text { Decannulated from } \\
\text { ECMO as no reversible } \\
\text { pathology }\end{array}$ & Died & $\begin{array}{l}\text { Respiratory } \\
\text { failure }\end{array}$ \\
\hline 5 & $\begin{array}{l}\text { Potter's } \\
\text { syndrome, } \\
\text { PPHN }\end{array}$ & 0 & 9 & 7 & Pulmonary hypoplasia & $\begin{array}{l}\text { Decannulated from } \\
\text { ECMO as no reversible } \\
\text { pathology }\end{array}$ & Survived & \\
\hline 6 & PPHN & 1 & 11 & $\mathrm{ECMO}+10$ & Pulmonary hypoplasia & $\begin{array}{l}\text { Withdrawal of intensive } \\
\text { care }\end{array}$ & Died & $\begin{array}{l}\text { Respiratory } \\
\text { failure }\end{array}$ \\
\hline 7 & PPHN & 2 & 5 & $\mathrm{ECMO}+2$ & $\begin{array}{l}\text { Alveolar capillary } \\
\text { dysplasia }\end{array}$ & $\begin{array}{l}\text { Withdrawal of intensive } \\
\text { care }\end{array}$ & Died & $\begin{array}{l}\text { Respiratory } \\
\text { failure }\end{array}$ \\
\hline 8 & $\begin{array}{l}\text { Meconium } \\
\text { aspiration }\end{array}$ & 7 & 6 & $\mathrm{ECMO}+7$ & $\begin{array}{l}\text { Meconium aspiration, } \\
\text { barotrauma }\end{array}$ & Treatment continued & Survived & \\
\hline
\end{tabular}

$\mathrm{PPHN}=$ persistent pulmonary hypertension of the newborn; $\mathrm{ECMO}=$ extracorporeal membrane oxygenation . 


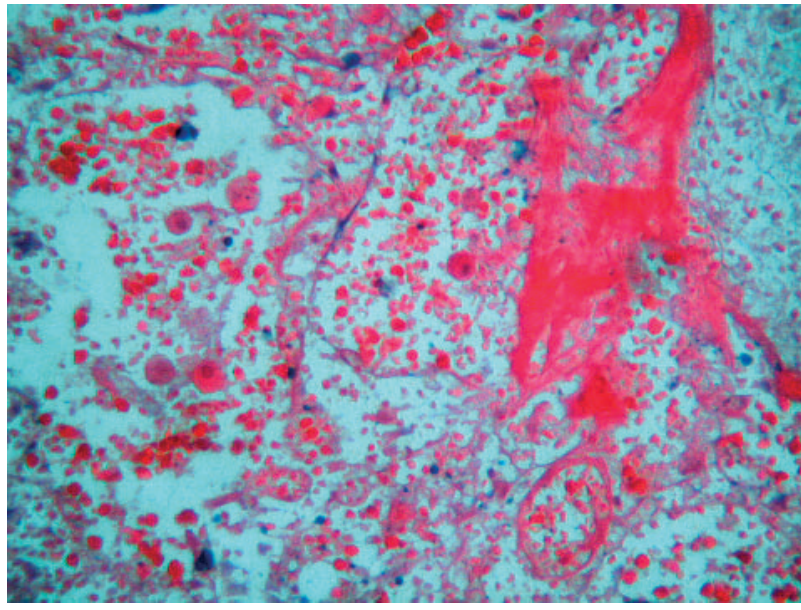

Figure 4 Pertussis. Lung infarction with complete loss of normal lung architecture.

was performed as ECMO was started in the operating room after failure to wean from cardiopulmonary bypass. The biopsy ruled out a fatal lung dysplasia and had no features of pulmonary hypertensive disease. A cardiac catheter performed after ECMO was commenced showed bilateral pulmonary artery stenosis which was successfully stented. This infant was weaned from ECMO support but died later from intracranial haemorrhage. The second infant (case 14) had preoperative pulmonary hypertension which responded to medical treatment. However, his pulmonary hypertension recurred following an arterial switch and ventricular septal defect closure performed at 5 weeks of age. A biopsy was performed in this infant 2 days later in the ICU. The biopsy specimen showed mild pulmonary hypertensive changes and the infant later died of progressive pulmonary hypertensive disease despite continuing active treatment. The third infant (case 15), who had total anomalous pulmonary venous drainage, was placed on ECMO preoperatively as she was impossible to oxygenate. Her biopsy specimen, which was taken after 3 days of ECMO, showed neither a lung dysplasia nor pulmonary hypertensive changes and, on the basis of this, treatment was continued. She survived her run on ECMO but died 2 weeks later from a low cardiac output state after reoperation for an obstructed pulmonary venous anastomosis (table 3 ).

\section{DISCUSSION}

We found that open lung biopsy has two broad roles in aiding decision making in patients referred for and on ECMO-to make a diagnosis of fatal lung dysplasia in neonates and to determine the presence of viable lung tissue in older infants with acute lung injury due to pertussis.

Our results demonstrated clinical usefulness in all the biopsies taken in the neonatal group. However, one infant with a histological diagnosis of pulmonary hypoplasia secondary to obstructive uropathy was taken off ECMO support as his lung disease was deemed irreversible but he was successfully weaned from mechanical ventilation and survived. This case shows that, even if histological examination of a biopsy specimen shows pulmonary hypoplasia, in this group of infants survival may still be possible as histology shows structure rather than function. In conditions such as pulmonary hypoplasia or pulmonary lymphangiectasia where long term survival may be possible, infants should continue to receive full support after weaning from ECMO. However, certain lung dysplasias such as alveolar capillary dysplasia ${ }^{34}$ and surfactant protein B deficiency ${ }^{5}{ }^{6}$ are irreversible and uniformly fatal. In these conditions, withdrawal of intensive care should be considered. We suggest that, in neonates referred for ECMO, if possible open lung biopsy should be performed before cannulation for ECMO if there is any suspicion that the diagnosis is a fatal lung dysplasia (for example, surfactant protein B deficiency or alveolar capillary dysplasia) and the patient's clinical condition allows. We suggest that in babies with PPHN who fail to improve after 10-14 days on ECMO, by which time reversible pathology such as meconium aspiration or congenital pneumonia should have resolved, the possibility of a fatal lung dysplasia should be considered and open lung biopsy performed. An algorithm for the use of open lung biopsy in persistent pulmonary hypertension of the newborn (PPHN) is shown in fig 5.

The usefulness of lung biopsy in determining the reversibility of acute lung injury in paediatric patients within the spectrum of ARDS is unclear. In this circumstance the biopsy specimen represents histological changes in a tiny section of lung in a disease that is known to be heterogeneous in nature $^{7}$ and which evolves over time, rather than the regenerative capacity of the whole lung. Furthermore, suspected irreversible acquired lung injury due to infections other than pertussis has been reported to resolve after prolonged periods of ECMO support lasting up to 6 weeks. ${ }^{8}$ In view of these considerations, our current practice is not to perform open lung biopsies to determine the reversibility of non-pertussis ARDS in older children on ECMO.

Acute lung injury due to pertussis, however, appears to have a unique natural history. A fatal outcome in pertussis is often associated with pulmonary hypertension, systemic hypotension, multi-organ failure, and seizures. This is followed by widespread pulmonary infarction which occurs 2-35 days after ECMO support is started. ${ }^{9-11}$ All three cases described here had one or more clinical features of fatal

Table 2 Paediatric ECMO cases

\begin{tabular}{|c|c|c|c|c|c|c|c|c|}
\hline $\begin{array}{l}\text { Case } \\
\text { no }\end{array}$ & $\begin{array}{l}\text { Admission } \\
\text { diagnosis }\end{array}$ & $\begin{array}{l}\text { Age at } \\
\text { referral } \\
\text { (days) }\end{array}$ & $\begin{array}{l}\text { Length of } \\
\text { ECMO run } \\
\text { (days) }\end{array}$ & $\begin{array}{l}\text { ECMO day } \\
\text { biopsy } \\
\text { performed }\end{array}$ & Histological diagnosis & Management change & Outcome & Cause of death \\
\hline 9 & $\begin{array}{l}\text { Pneumovirus } \\
\text { ARDS }\end{array}$ & 2116 & 12 & 11 & Fibroproliferative ARDS & Treatment continued & Died & Respiratory failure \\
\hline 10 & Pertussis & 34 & 17 & 14 & Lung infarction & $\begin{array}{l}\text { Withdrawal of } \\
\text { intensive care }\end{array}$ & Died & Respiratory failure \\
\hline 11 & Pertussis & 25 & 38 & 17 & Fibroproliferative ARDS & Treatment continued & Died & Respiratory failure \\
\hline 12 & Pertussis & 66 & 32 & 28 & Lung infarction & $\begin{array}{l}\text { Withdrawal of } \\
\text { intensive care }\end{array}$ & Died & Respiratory failure \\
\hline
\end{tabular}




\begin{tabular}{|c|c|c|c|c|c|c|c|c|}
\hline Case no & Admission diagnosis & $\begin{array}{l}\text { Age at } \\
\text { referral } \\
\text { (days) }\end{array}$ & $\begin{array}{l}\text { Length of } \\
\text { ECMO run } \\
\text { (days) }\end{array}$ & $\begin{array}{l}\text { ECMO day } \\
\text { biopsy } \\
\text { performed }\end{array}$ & $\begin{array}{l}\text { Histological } \\
\text { diagnosis }\end{array}$ & Management change & Outcome & Cause of death \\
\hline 13 & $\begin{array}{l}\text { TGA, pulmonary } \\
\text { hypertension postop }\end{array}$ & 17 & 8 & 1 & $\begin{array}{l}\text { Non-specific } \\
\text { features }\end{array}$ & Treatment continued & Died & $\begin{array}{l}\text { Intracranial } \\
\text { haemorrhage }\end{array}$ \\
\hline 14 & $\begin{array}{l}\text { TGA, VSD, pulmonary } \\
\text { hypertension postop }\end{array}$ & 28 & 11 & 2 & $\begin{array}{l}\text { Mild pulmonary } \\
\text { hypertensive } \\
\text { changes }\end{array}$ & Treatment continued & Died & $\begin{array}{l}\text { Pulmonary } \\
\text { hypertension }\end{array}$ \\
\hline 15 & TAPVD & 1 & 9 & 3 & $\begin{array}{l}\text { Non-specific } \\
\text { features }\end{array}$ & Treatment continued & Died & $\begin{array}{l}\text { Low cardiac output } \\
\text { state following } \\
\text { reoperation for } \\
\text { TAPVD }\end{array}$ \\
\hline
\end{tabular}

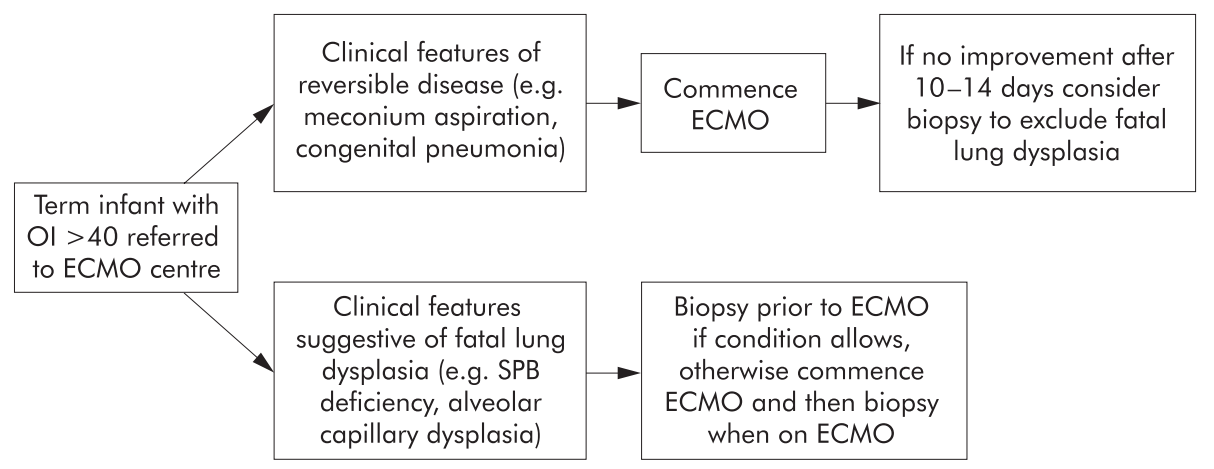

Figure 5 Algorithm for open lung biopsy in persistent pulmonary hypertension of the newborn (PPHN).

pertussis and all developed histological changes of lung infarction (although in case 11 these changes were only found on post mortem examination). Survival has been reported with ECMO runs of up to 29 days in pertussis but 13 of the 16 survivors so far reported to the Extracorporeal Life Support Organisation (ELSO) were decannulated after less than 21 days of ECMO. ${ }^{12}$ We therefore suggest that a lung biopsy should be considered in infants with pertussis who fail to improve after 3-4 weeks of lung rest on ECMO. If the biopsy reveals lung infarction, the chest radiograph shows a diffuse process, and other features of fatal disease are present, we would advocate withdrawal of intensive care.

The aim of performing a lung biopsy in infants on ECMO following cardiac surgery was to exclude an associated fatal lung dysplasia or pulmonary vascular disease. However, the clinical usefulness of this is impossible to determine from the small number of cases in our series.

In spite of our concerns regarding safety, no patient died as a result of open lung biopsy and postoperative bleeding occurred in only one patient. This bleeding did not contribute to that patient's death. Air leak was not a complication in any patient, perhaps because of the low lung compliance and the low inflation pressure delivered by the ventilator during ECMO support. Our finding that open lung biopsy is a safe procedure to perform in patients on ECMO is in concordance with that of Jaklitsch et al ${ }^{13}$ who performed open lung biopsies on eight patients on ECMO and also reported no complications.

There have been five previous reports of open lung biopsy during ECMO in children. Ombrellaro et al $^{14}$ reported a single case of an 11 month old burns victim with ARDS in whom a biopsy was performed before ECMO cannulation. The biopsy specimen showed severe but histologically reversible lung disease and, as a consequence, the patient was placed on ECMO and survived. Bond et al ${ }^{15}$ reviewed eight infants and children who had open lung biopsies performed while receiving ECMO support for respiratory failure and found that, in five cases, the biopsy results led to major treatment interventions. Ryan and Finer ${ }^{16}$ reviewed the ELSO registry from 1986 to 1994 and found 18 infants in whom open lung biopsies had been performed while receiving ECMO from the 6000 neonatal cases in the registry for that period ( 3 per 1000 ECMO patients). They confirmed the usefulness and safety of open lung biopsy in patients on ECMO when the diagnosis was not certain or when the infant was not improving, but were unable to comment in detail on the histological findings as the data were not available in the ELSO registry. Jaklitsch et $a l^{13}$ performed open lung biopsies on eight infants and children on ECMO but they neither reported the histological findings in detail nor discussed the optimum timing for biopsy. Cassidy et al ${ }^{1}$ reviewed the UK experience of neonatal respiratory failure from 1997 to 2000 and found that, of 173 term infants who received ECMO for respiratory failure, 10 had an underlying lung dysplasia which was incompatible with life. They suggested that open lung biopsy and surfactant protein analysis should be performed on any neonate who was unable to be weaned from ECMO support within 10 days to 2 weeks.

Our results suggest that open lung biopsy is safe whether performed before, during or after ECMO. Lung biopsy is of greatest use in the neonatal population for excluding a fatal lung dysplasia. It also has a role in infants with pertussis who fail to improve after 3-4 weeks of ECMO support, to confirm the presence of viable lung tissue. The clinical usefulness of lung biopsy in patients with non-pertussis ARDS and in infants following cardiac surgery remains uncertain. 
Authors' affiliations

D Inwald, Portex Unit, Institute of Child Health, London WCIN IEH, UK K Brown, F Gensini, A Goldman, Cardiac Intensive Care Unit, Great Ormond Street Hospital for Children NHS Trust, London WCIN 3JH, UK M Malone, Histopathology Department, Great Ormond Street Hospital for Children NHS Trust, London WCIN 3JH, UK

\section{REFERENCES}

1 Cassidy J, Smith J, Goldman A, et al. The incidence and characteristics of neonatal irreversible lung dysplasia. J Pediatr 2002;141:426-8.

2 deMello DE, Nogee LM, Heyman S, et al. Molecular and phenotypic variability in the congenital alveolar proteinosis syndrome associated with inherited surfactant protein B deficiency. J Pediatr 1994; 125:43-50.

3 Kane TD, Greenberg JM, Bove KE, et al. Alveolar capillary dysplasia with misalignment of the pulmonary veins: a rare but fatal cause of neonatal respiratory failure. Pediatr Surg Int 1998;14:89-91.

4 Al Hathlol K, Phillips S, Seshia MK, et al. Alveolar capillary dysplasia. Report of a case of prolonged life without extracorporeal membrane oxygenation (ECMO) and review of the literature. Early Hum Dev 2000;57:85-94.

5 Nogee LM, de Mello DE, Dehner LP, et al. Brief report: deficiency of pulmonary surfactant protein B in congenital alveolar proteinosis. N Engl J Med 1993;328:406-10.
6 Moulton SL, Krous HF, MerrittTA, etal. Congenital pulmonary alveolar proteinosis: failure of treatment with extracorporeal life support. J Pediatr 1992; 120:297-302.

7 Gattinoni L, Presenti A, Torresin A, et al. Adult respiratory distress syndrome profiles by computed tomography. J Thorac Imaging 1986;1:25-30.

8 Linden V, Palmer K, Reinhard J, et al. High survival in adult patients with acute respiratory distress syndrome treated by extracorporeal membrane oxygenation, minimal sedation, and pressure supported ventilation. Intensive Care Med 2000;26:1630-7

9 Williams GD, Numa A, Sokol J, et al. ECLS in pertussis: does it have a role? Intensive Care Med 1998;24:1089-92.

10 Pierce C, Klein N, Peters $M$. Is leukocytosis a predictor of mortality in severe pertussis infection? Intensive Care Med 2000;26:1512-4.

11 Pooboni S, Roberts N, Westrope C, et al. Extracorporeal life support in pertussis. Pediatr Pulmonol 2003;36:310-5

12 ELSO. ECMO Registry of the Extracorporeal Life Support Organization (ELSO). Ann Arbor, Michigan, November 2003

13 Jaklitsch MT, Linden BC, Braunlin EA, et al. Open-lung biopsy guides therapy in children. Ann Thorac Surg 2001;71:1779-85.

14 Ombrellaro M, Goldthorn JF, Harnar TJ, et al. Extracorporeal life support for the treatment of adult respiratory distress syndrome after burn injury. Surgery 1994; 115:523-6.

15 Bond SJ, Lee DJ, Stewart DL, et al. Open lung biopsy in pediatric patients on extracorporeal membrane oxygenation. J Pediatr Surg 1996:31:1376-8.

16 Ryan CA, Finer NN. Open lung biopsies in neonates on ECMO: additional cases. Extracorporeal membrane oxygenation. J Pediatr Surg 1998;33:1327-8.

\section{LUNG ALERT}

\section{Genetic make up and environmental factors in the pathogenesis of allergic disorders}

$\Delta$ Gilliland FD, Li Y, Saxon A, et al. Effect of glutathione-S-transferase M1 and P1 genotype on xenobiotic enhancement of allergic responses: randomised, placebo-controlled crossover study. Lancet 2004;363:119-25

$\mathrm{t}$ is well known that air pollution increases morbidity from asthma and other allergic disorders. The genetic factors that underlie this process are complex and poorly understood. Oxidative stress has emerged as an important mechanism in the toxic effects of environmental pollution. The ability of an individual to neutralise these reactive oxygen species seems to be important in modifying allergic responses. Members of the enzyme glutathione S-transferase superfamily (GSTMl, GSTT1, and GSTPl) provide the major defence system against oxidative stress.

Gilliland and colleagues conducted a randomised, placebo controlled, crossover study to test the hypothesis that null genotypes for GSTMl, GSTT1, and GSTPl codon 105 variants are the key genotypes that combat the oxidative stress. Nineteen atopic volunteers were included in the study. They had intranasal challenges with either allergen plus placebo or allergen plus diesel exhaust particles. The allergic response was observed by measuring surrogate markers of allergic response (IgE, histamine, interleukin-4, interferon- $\gamma$ ). Genotypes were identified in all the participants. The results showed that the participants with null GSTMI or GSTPl wild type had an enhanced nasal allergic response to diesel exhaust particles with a statistically significant rise in surrogate markers. This suggests that polymorphism in genotypes affects the defensive response against oxidative stress.

This important study suggests a direct way in which pollution could be triggering an allergic response. This susceptibility seems to be regulated by genetic factors and hence opens up the possibility of new therapeutic interventions.

A Khan Specialist Registrar in Respiratory Medicine, Derriford Hospital, Plymouth, UK iyazkhan@aol.com 